\title{
Challenges in developing polymer flocculants to improve bitumen quality in non-aqueous extraction processes: an experimental study
}

\author{
Daniel V. Dixon ${ }^{1} \cdot$ Stanislav R. Stoyanov ${ }^{2} \cdot{\text { Yuming X } \mathrm{Xu}^{2} \cdot \text { Hongbo Zeng }^{1} \cdot \text { João B. P. Soares }}^{1}$
}

Received: 26 July 2019 / Published online: 10 February 2020

(c) The Author(s) 2020

\begin{abstract}
Western Canada's oil sands hold the third-largest hydrocarbon deposits in the world. Bitumen, a very heavy petroleum, is currently recovered by surface mining with warm water or in situ. Recovery processes that use organic solvents are being developed to reduce water usage and tailings production. While solvent-based methods can effectively extract bitumen, removal of residual fine solids from diluted bitumen product (DBP) to meet the pipeline transport requirement of $<0.5 \mathrm{wt} \%$ solids and water in DBP remains a major challenge. We propose a novel area of application of polymer flocculants for fine solids removal from DBP. In principle, polymer flocculants can be applied to help remove these residual solids in conjunction with physical separation processes to increase process effectiveness and energy efficiency. Several polymers are selected and screened for flocculation behavior using kaolinite suspended in DBP and toluene, as a model system. Focused beam reflectance measurements and force tensiometer techniques are used to determine flocculation and sedimentation in DBP. The observed flocculation and sedimentation rate enhancements indicate that the polymers tested have only minor effects, providing opportunities for advanced polymer development. These findings exemplify the challenges in identifying polymers that may be effective as flocculants in heavy petroleum media.
\end{abstract}

Keywords Non-aqueous extraction · Diluted bitumen · Oil-soluble polymer flocculants · Sedimentation in dark and opaque media $\cdot$ Focused beam reflectance measurements

\section{Introduction}

For several decades, bitumen has been extracted from oil sands in Alberta by surface mining using variations of the modified Clark hot water extraction process (Clark and Pasternack 1932). This process is energy intensive, as up to 10

Edited by Xiu-Qiu Peng

Electronic supplementary material The online version of this article (https://doi.org/10.1007/s12182-019-00414-z) contains supplementary material, which is available to authorized users.

Stanislav R. Stoyanov

stanislav.stoyanov@canada.ca

Hongbo Zeng

hongbo.zeng@ualberta.ca

$\checkmark$ João B. P. Soares

jsoares@ualberta.ca

1 Department of Chemical and Materials Engineering, University of Alberta, 9211-116 Street NW, Edmonton, AB T6G 1H9, Canada

2 CanmetENERGY Devon, Natural Resources Canada, 1 Oil Patch Drive, Devon, AB T9G 1A8, Canada volumes of water need to be heated per volume of bitumen produced. The process also yields fluid fine tailings (FFT) that are currently stored in tailings ponds for decades and must undergo further intensive dewatering before the solids can be reclaimed as a dry landscape. Recent estimates show that tailing ponds (including dykes, berms, and beaches) already occupy over $220 \mathrm{~km}^{2}$ of land in Alberta (Lower Athabasca Region 2015). The remediation of tailings ponds is an area of active research, with polymeric flocculants being used in most commercial tailings treatment technologies (Botha and Soares 2015; Vedoy and Soares 2015).

Alternatives to the modified Clark process are actively being investigated, with the aim of reducing energy and water usage. Of particular interest are non-aqueous bitumen extraction processes based on organic solvents intended to 
eliminate water use and long-term tailings storage (Lin et al. 2017). Non-aqueous extraction processes, however, face challenges in solvent recovery and solids migration to the bitumen product (Lin et al. 2017). Process aids, such as polymers, are one approach that may improve the efficiency of non-aqueous bitumen extraction processes (Lin et al. 2017).

Both commercial extraction processes and pilot-scale non-aqueous extraction processes currently require an additional solids removal step before the bitumen product can be transported by pipeline (Rao and Liu 2013; Lin et al. 2017). The use of polymers as flocculants in organic media and in oil applications, have been, to the authors' knowledge, largely underexplored as a means of flocculating solids in these media, with previous studies being restricted to model systems (Ngnie et al. 2018).

Polymer flocculants have been used successfully to remove solids at lower energy costs than mechanical separations in waste water treatment, mineral processing, pulp and paper (Gregory and Barany 2011) as well as in treatment of FFT from oil sand mining operations. Process aids consisting mainly of polyacrylamides (PAMs) have been investigated to improve the overall processing of low-grade ores (Li et al. 2005, 2008; Long et al. 2011). Polymers are used in bitumen froth treatment as demulsifiers to facilitate the coalescence of water droplets and allow for bitumen-water phase separation (Ese et al. 2000; Wu et al. 2005; Pensini et al. 2014; Tchoukov et al. 2014). Typically, polymer flocculation involves the adsorption of a polymer onto the surface of colloidal particles, where it can then act as a bridge between particles, resulting in aggregation and destabilization of the suspension. The flocculation process is sometimes enhanced via charge neutralization if the polymer subunits and the particles are oppositely charged (Szilagyi et al. 2014; Vedoy and Soares 2015). Higher-molecular-weight polymers improve particle settling rates due to the formation of longer/multiple bridges between mineral particles. Most flocculation applications call for water-soluble polymers and polyelectrolytes that are insoluble in bitumen. However, the principles of aqueous flocculation should be applicable for the development and optimization of oil-soluble polymer flocculants for the removal of fines from diluted bitumen products (Napper 1968; Ngnie et al. 2018).

Of particular interest are polymer flocculants that have been used in the oil sands industry to treat FFT and mature fine tailings (MFT), a topic covered in recent reviews (Vedoy and Soares 2015; Vajihinejad et al. 2019). Most flocculants used to treat FFTs are derived from PAMs, which can by synthesized as neutral, anionic, or cationic polymers (Long et al. 2006; Li et al. 2015; Lu et al. 2015, 2016a, b; Vedoy and Soares 2015; Reis et al. 2016; Botha et al. 2017; Zhu et al. 2017). This flexibility has allowed PAMs to be used in a variety of systems that may require different charge characteristics. Additionally, PAMs can be synthesized with exceptionally high molecular weights $\left(>10^{6} \mathrm{~g} / \mathrm{mol}\right)$, which makes these polymers even more effective as bridging flocculants (Gregory and Barany 2011; Vedoy and Soares 2015). In polymer applications for flocculation of solids out of bitumen, a major challenge would be to select polymers that adsorb on mineral solids but that are also soluble in oil.

\section{Polymer flocculant selection}

Many of the properties that make a demulsifier surfaceactive are analagous for polymer flocculants. Surface-active components are required for efficient adsorption of the polymer chains onto the clay particle surfaces. However, unlike demulsifiers, flocculants must be composed of long polymer chains so that the free end of an adsorbed polymer molecule may attach to other particles and form large flocs (Dickinson and Eriksson 1991). To meet the requirement of less than $0.5 \mathrm{wt} \%$ solids and water in diluted bitumen, the ideal flocculant must be soluble in diluted bitumen, form dense flocs with mineral solids that will settle out of the bitumen phase, preferentially adsorb to clay and other mineral particles over bitumen, and lead to a sediment that dries easily. The latter characteristic would minimize the retention of solvent in the settled solids. Ideally, this should be accomplished at the lowest possible dosage and material cost.

Intermolecular interactions are central to understanding how solids migrate into bitumen and how polymer flocculants operate. To better understand the hierarchy of intermolecular forces acting in these systems, further knowledge of the chemical structures of the solids and polymer flocculant, and of solvation thermodynamics is needed. Electrostatic and dispersion forces play key roles in interactions among the system components. Moreover, an understanding of the mechanism of formation of polymer bridges between particles and the forces that arise due to the bridging interactions, as well as the mixing energy in the system, are required in order to describe the interactions in the system (Dickinson and Eriksson 1991).

Polymer bridging is the process by which a polymer molecule adsorbs onto one particle, and then a tail or loop of the adsorbed polymer adheres to other particle(s). If the bridging force is sufficient, the particles will remain in close proximity and form a floc that can then settle out of the mixture. Attractive bridging forces have been measured for polymer flocculants used in tailings treatments (Lu et al. 2015, 2016b; Wang et al. 2015). While bridging is the main mechanism for polymer-mediated flocculation, electric double-layer forces may also play a significant role for electrostatically stabilized suspensions. These suspensions can often be flocculated through charge neutralization, electrostatic patching, or in combination with polymer bridging (Dickinson and Eriksson 1991). 
For these cases, polyelectrolytes are the most useful additives because they interact strongly with charged particles that need to be separated. Adsorbed polymers are more likely to stay attached to an oppositely charged surface, and the net surface charge of the polymer-coated surfaces may be neutralized at the right dosage of polyelectrolyte. Complete coating of a charged particle with an oppositely charged polymer is not necessary for flocculation. If only patches of opposite charge are formed, the enhanced electrostatic attraction between the particles may still create better opportunities for polymer bridging (Gregory 1973; Dickinson and Eriksson 1991).

Electrostatic effects are prominent in aqueous solutions, where ions are readily soluble and hydronium cations may freely dissociate from some functional groups, stabilized by water and free ions. This is not the case in nonpolar solvents, where the dielectric constants are very low $(\sim 0.2)$. As a result, in nonpolar media, electrostatic interactions typically play a smaller role compared to other interactions such as polymer bridging, steric forces, and hydrophobic interactions (Morrison 1993; Berg 2010).

The choice of solvent can have a significant effect on the stability of a mineral suspension and the performance of a polymer flocculant. The interactions among polymer, solids, solvent, and the interfacially active components of bitumen, such as asphaltenes, all contribute to flocculation performance. Toluene is considered a good solvent for asphaltenes, the component of bitumen that is known to stabilize emulsions and suspended solids (Marlow et al. 1987). In toluene-based systems, asphaltenes at surfaces create a repulsive steric barrier between particles due to the swelling of the asphaltene layer (Wang et al. 2009; Natarajan et al. 2011). In the presence of heptane, a poor solvent for asphaltenes, the asphaltene layers are not extended and there is only a small attractive force between asphaltene-coated surfaces (Natarajan et al. 2011).

Moreover, the choice of solvent in the diluted bitumen would have a substantial effect on the thermodynamics of polymer adsorption. As described by the mean field theories of polymer adsorption, and the Flory-Huggins solution theory, the quality of the solvent can affect the conformation of polymers and the energetic driving force behind adsorption. For good flocculation performance, the polymer would need to outcompete adsorption of both solvent and bitumen components that may also interact with mineral surfaces.

When choosing a class of polymers to work with, the use of solubility parameters may be helpful in guiding the selection of materials that are compatible with bitumen-solvent mixtures. The solubility parameter, first introduced by Hildebrand and Scott, is derived from the cohesive energy density of a pure substance and estimated using the following equation (Hansen 2007):
$\delta=\left(\frac{\Delta H_{v}-R T}{V}\right)^{\frac{1}{2}}$

where $\delta$ is the Hildebrand solubility parameter, $\Delta H_{v}$ is the enthalpy of vaporization, $R$ is the gas constant, $T$ is the absolute temperature, and $V$ is the molar volume. According to this theory, materials having similar solubility parameters are miscible with one another. This theory is limited when it comes to polymers because the enthalpy of vaporization cannot be measured in polymeric materials, as they degrade when heated. The solubility parameters of polymers can be calculated by indirect methods based on solvent testing, swelling values, refractive index, intrinsic viscosity, or inverse gas chromatography. These can still serve to qualitatively predict behavior or guide experiments.

When selecting solvents for the extraction of bitumen, Pal et al. (2015) and Nikakhtari et al. (2013) have come to close agreement on what solubility parameter would be ideal for solvent-bitumen mixtures. Pal et al. (2015) determined that the solvent solubility parameter should fall between $16.45 \mathrm{MPa}^{1 / 2}$ and $16.65 \mathrm{MPa}^{1 / 2}$ to minimize fines in bitumen, and Nikakhtari et al. (2013) determined that solubility parameters above $16.5 \mathrm{MPa}^{1 / 2}$ are best to reduce fines migration into bitumen. A polymer selected in this range may also be soluble in diluted bitumen. Some polymers in this range include polyethylene $\left(16.2-16.6 \mathrm{MPa}^{1 / 2}\right)$, polyisoprene $\left(15.8-16.68 \mathrm{MPa}^{1 / 2}\right)$, and polyisobutene (16.06-16.47 $\mathrm{MPa}^{1 / 2}$ ) (2007). These polymers all fall under the class of polyolefins and have been used widely in the oil industry as drag reducers for pipelines. They share some characteristics with the desired attributes of polymers for flocculation of fine solids in the bitumen extraction process, namely they should be of high molecular weight (greater than $10^{6} \mathrm{~g} / \mathrm{mol}$ ), amorphous, and readily soluble in oil (Mowla and Naderi 2006).

A purely oil-soluble hydrophobic polymer, however, cannot be used in flocculation applications, because the polymer would favor remaining in the bulk oil phase instead of adsorbing onto clay or other mineral solids. These solids are negatively charged in water and would still be partially negatively charged in bitumen, because clays could retain some water from the oil sand ore. Therefore, the target polymer flocculant would also require some polar end groups or blocks of hydrophilic polymer to facilitate adsorption onto fine solids. Figure 1 illustrates some possible arrangements of hydrophilic and hydrophobic monomers. Systems, such as hydrolyzed polyethylene (Botha et al. 2017), blocks of PEO/ PPO (Pensini et al. 2014; Reis et al. 2016), or temperatureresponsive changes in hydrophobicity (Long et al. 2011; Lu et al. 2015), have all been used in the treatment of mineral tailings and have the potential to work in the removal of solids from bitumen in a non-aqueous extraction process. 


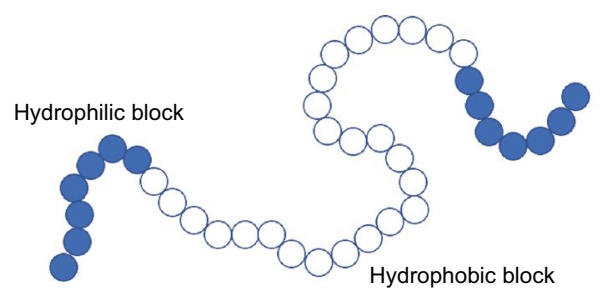

(a)

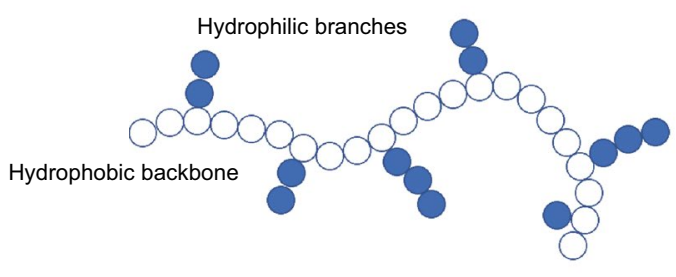

(b)

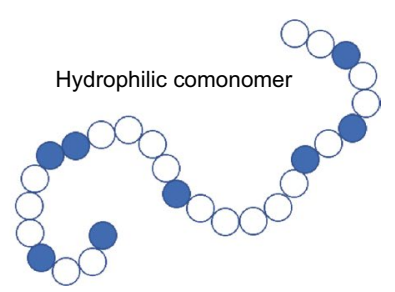

(c)

Fig. 1 Schematic diagram of possible polymer flocculant structures. a Block copolymer with hydrophobic chain and hydrophilic chain ends. b Hydrophobic polymer with hydrophilic branches. $\mathbf{c}$ Random copolymer with hydrophobic and hydrophilic monomers

Herein, we explore the challenges faced when developing polymer flocculants to improve bitumen product quality and support the industrial implementation of non-aqueous recovery processes. An evaluation of several flocculant systems for solids removal is presented in the context of the challenges of observing fine solids settling in dark bitumen media. Moreover, criteria for the design of polymer flocculants to settle fine particles out of diluted bitumen are outlined, based on knowledge gained from the use of flocculants in different stages of the modified Clark process.

\section{Materials and methods}

\subsection{Materials}

Organic solvents used in this study, toluene and cyclohexane, were purchased from Sigma-Aldrich and used without further purification. Kaolinite was purchased from Acros Organics. Bitumen, free of solids, was obtained from an oil sands operator and used as is. Ethyl cellulose, poly(ethylene glycol)-block-poly(propylene glycol)block-poly(ethylene glycol) $\left(M_{n} \sim 5800\right)$, (hydroxypropyl)methyl cellulose, poly(ethylene oxide) $\left(M_{w} \sim 1 \mathrm{M}\right)$, polystyrene $\left(M_{w} \sim 350,000\right)$, methyl acrylate, amylopectin, and hydroxyethyl cellulose were purchased from Sigma-Aldrich. Hyperbranched functionalized polyethylene (HBfPE) (5\% methyl acrylate) was synthesized in our group, as described elsewhere (Botha et al. 2017). Polystyrene sulfonate was modified according to the procedure detailed in Mazzeo et al. (Mazzeo et al. 2018).
Ethylene-propylene-diene terpolymers (EPDM) (3\%-6\% diene content) were supplied by DOW Chemical Co., and modified using 9-borabicyclo[3.3.1]nonane and hydroxylated with $\mathrm{NaOH} / \mathrm{H}_{2} \mathrm{O}_{2}$ (Chung et al. 1994).

\subsection{Solubility screening}

Polymer solubility was determined qualitatively based on cloud point observations at room temperature, at concentrations of $2 \mathrm{mg} / \mathrm{mL}$ (Mazzeo et al. 2018). Both toluene and cyclohexane were used as solvents to screen the viability of the polymer flocculants. Initially, the polymer solutions were mixed for up to $24 \mathrm{~h}$ at room temperature. If the polymer appeared insoluble, or if the solution remained cloudy, the temperature was raised to $50{ }^{\circ} \mathrm{C}$ and stirred for an additional $24 \mathrm{~h}$. All solutions were cooled to room temperature before final observations were made.

\subsection{Preparation of model suspensions}

Kaolinite particles were prepared as a $2 \%$ w/w suspension in bitumen/toluene solution $(10 \% \mathrm{w} / \mathrm{w})$. This mixture was stirred at room temperature overnight at $250 \mathrm{rpm}$ to ensure sufficient adsorption of bitumen on the kaolinite particles. The suspensions were then sonicated for $1 \mathrm{~min}$ and mixed again for an additional $30 \mathrm{~min}$. These suspensions were then used in particle size and sedimentation measurements. 


\subsection{FBRM monitoring}

Focused beam reflectance measurement (FBRM) is an optical technique for the characterization of particle sizes (chord lengths). It is useful for in situ monitoring of particles ranging in size from $1 \mu \mathrm{m}$ to $1 \mathrm{~mm}$. The technique relies on the reflectance of a laser light and thus can be used in dark or highly concentrated solutions, where absorbance or light scattering measurements are typically unreliable. In oil sands applications, the FBRM technique has been successfully used for the characterization and performance measurement of a number of flocculants used for mature fine tailings treatments (Gumfekar and Soares 2018; Vajihinejad and Soares 2018).

Model suspensions were prepared and used for chord length distribution monitoring. The suspensions were mixed at $200 \mathrm{rpm}$ in a $250 \mathrm{~mL}$ beaker and monitored in real time with an FBRM probe. The polymer was added as a $2 \mathrm{mg} / \mathrm{mL}$ solution in toluene to the suspension under the same mixing conditions, and the chord length distribution of the particles were continuously recorded, as the polymer dose was increased from $500 \mathrm{mg}$ polymer $/ \mathrm{kg}$ solids up to $50,000 \mathrm{mg}$ polymer/kg solids.

\subsection{Sedimentation}

A Krüss K100 force tensiometer with a sedimentation probe-a highly sensitive balance with a probe immersed in the solution where particles can accumulate on a dishwas used to measure mass accumulation over time. This technique has proved useful to monitor the sedimentation of silica microparticles in aqueous solutions and in organic media treated with bitumen (Gupta and Basu 2005; Karkooti 2014). Model suspensions were transferred to a dish in the force tensiometer and polymer was then added to the suspension under constant mixing for $1 \mathrm{~min}$ before mixing was stopped, and the sedimentation probe was immersed in the suspension to monitor mass accumulation. Figure 2 depicts the experimental setup.

\section{Results and discussion}

\subsection{Polymer solubility evaluation}

The polymers in Fig. 3 were first evaluated for solubility in toluene and cyclohexane. A viable polymer for flocculation needs to be readily dispersible in diluted bitumen at operating temperatures. The first candidate was a recently developed HBfPE, a polyethylene copolymerized with methyl acrylate having a hyperbranched structure (Botha et al. 2017). This polymer was selected, because it had been developed as a flocculant to treat MFT and, being

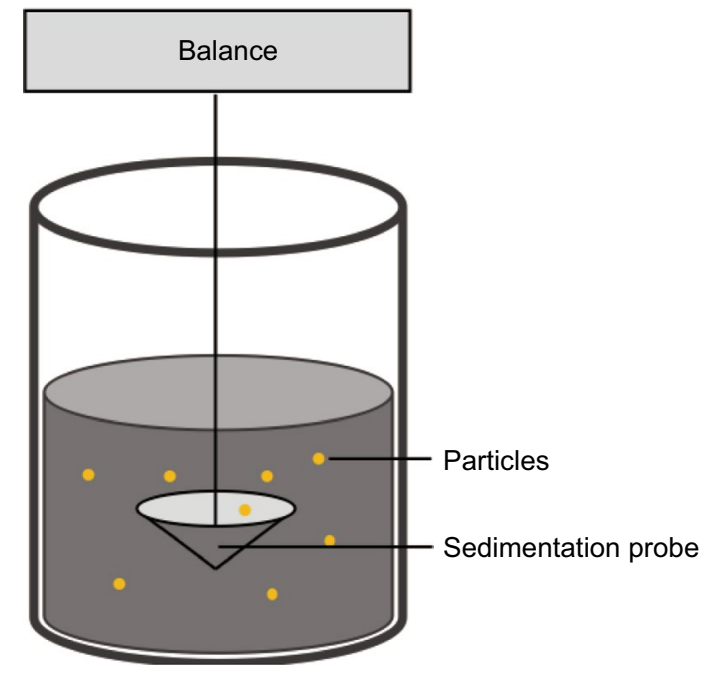

Fig. 2 Schematic diagram of force tensiometer with sedimentation probe

polyethylene-based, would be more easily soluble in oil. The HBfPE used to treat MFT had a methyl acrylate content above $35 \%$, to allow for dispersion in water, but for an oil-soluble variant a lower methyl acrylate content was desired. Analogous to HBfPE, where a hydrophobic polymer was functionalized with a more hydrophilic monomer, a second type of polymer based on the synthetic rubber EPDM was modified to add hydroxyl functionality (EPDM-OH). A third type of polymer chosen for screening was a triblock poly(ethylene oxide)-poly(propylene oxide)-poly(ethylene oxide) (PEO-PPO-PEO). Polymers of this class are used as surfactants and demulsifiers. In fact, many PEO-PPO-PEO linear and star polymers are used in oil sands froth treatment to break emulsions (He et al. 2015). Our hypothesis was that the surface-active nature of these polymers and the ability to tune their hydrophobicity by changing the ratio of PEO to PPO could make them good candidates if they could be synthesized with sufficiently high molecular weights. Poly(methyl acrylate) (PMA) homopolymer was also tested for solubility. PMA has been used as part of grafted copolymers of PAMs and EPDMs, as mentioned above. This screening was conducted to determine if the PMA homopolymer could act as a flocculant in this system. Poly(styrene sulfonate) (PSS) was also tested with 7\% of the sub-units sulfonated. Polystyrene is oil soluble, and its sulfonated derivative is highly charged, improving solubility in water at high degrees of sulfonation; at low degrees of sulfonation the polymer remains soluble in toluene. A number of natural polymers that have been used in the oil industry as demulsifiers-ethyl cellulose (EC), hydroxypropyl methyl cellulose (HPMC), amylopectin (AMP), and hydroxyethyl cellulose (HEC)—-were also included in these screening experiments (He et al. 2015). 
<smiles>CC(C)(C)CCC(C)(C)C(C)(C)CCC(C)(C)C</smiles>

HBfPE<smiles>CC(C)OCCC(C)(C)OC(C)CC(C)(C)OCCC(C)(C)C</smiles>

PEO-PPO-PEO<smiles>CC(C)(C)CC(c1ccc(S(=O)(=O)[O-])cc1)C(C)(C)C</smiles>

PSS

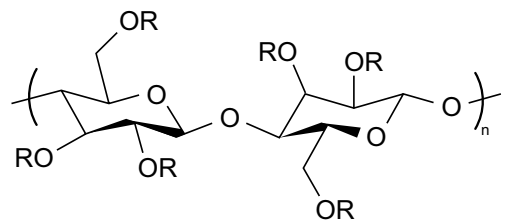

$\mathrm{R}=\mathrm{H}$ or $\mathrm{CH}_{2} \mathrm{CH}_{3}$

EC<smiles>[R]C[C@H](OC(OC(C)(C)C)[C@@H](OC(C)(C)C)C([R])O)C([R])O</smiles>

$\mathrm{R}=\mathrm{H}$ or $\mathrm{CH}_{3}$ or $\mathrm{CH}_{2} \mathrm{CH}(\mathrm{OH}) \mathrm{CH}_{3}$

HPMC

PEO

Fig. 3 Polymer structures for the screening experiments: HBfPE hyperbranched functionalized polyethylene, EC ethyl cellulose, HPMC hydroxypropyl methyl cellulose, PMA poly(methyl acrylate), PSS polystyrene sulfonate, EPDM-OH hydroxylated ethylene propylene diene, $P E O-P P O-P E O$ poly(ethylene oxide)-poly(propylene oxide)-poly(ethylene oxide) and $P E O$ poly(ethylene oxide)

Among these polymers, three were found to be soluble (clear solution at room temperature) in toluene, and five were found to be slightly soluble (cloudy solution at room temperature, but soluble at elevated temperatures) in toluene (Table 1). Only HBfPE was completely soluble in cyclohexane, one of the more effective solvents for

Table 1 Solubility of $2 \mathrm{mg} / \mathrm{mL}$ of polymer in toluene and cyclohexane

\begin{tabular}{llll}
\hline Polymer & Description & Toluene soluble & Cyclohexane soluble \\
\hline HBfPE & Hyperbranched functionalized polyethylene & Yes & Sparingly \\
EC & Ethyl cellulose & Yes & No \\
PMA & Poly(methyl acrylate) & Sparingly & Sparingly \\
PEO-PPO-PEO & Poly(ethylene oxide)-block-poly(propylene oxide)-block- & Yes & Sparingly \\
& poly(ethylene oxide) & & No \\
HPMC & Hydroxypropyl methyl cellulose & Sparingly & No \\
PEO & Poly(ethylene oxide) & Sparingly & Yes \\
PSS & Polystyrene sulfonate & Sparingly & No \\
EPDM-OH & Hydroxylated ethylene-propylene-diene terpolymer & Sparingly & No \\
AMP & Amylopectin & No & No \\
HEC & Hydroxyethyl cellulose & No & No \\
PAM-PEO & Polyacrylamide-graft-poly(ethylene oxide) & & \\
\hline
\end{tabular}


non-aqueous extraction processes (Nikakhtari et al. 2013). These findings further demonstrate the challenge in identifying polymers that may be effective in oil-based media. Even at low degrees of polar functionalization, many of the tested polymers become difficult to disperse in toluene and are insoluble in cyclohexane. The eight toluene-soluble polymers were used in further tests to evaluate the flocculation and sedimentation of kaolinite using the FBRM and force tensiometer techniques.

\subsection{Chord length distribution monitored via FBRM}

Figure 4 presents the chord length distribution of kaolinite particles used for flocculation screening determined using FBRM. Kaolinite is the most common clay material found in bitumen (Kaminsky et al. 2009), so screening for its flocculation was used as a starting point in this comparative investigation.

Kaolinite particles have a bimodal chord length distribution, which is consistent with the laser diffraction data. The FBRM measurements done in toluene show that kaolinite exists in larger aggregates compared to the kaolinite samples measured in water (Fig. 4). This observation is consistent with the fact that kaolinite is more readily dispersible in water, where the clay can more readily participate in hydrogen bonding with water. In nonpolar solvents, the kaolinite particles would more likely be attracted to themselves than to the solvent in the system. This phenomenon has been demonstrated in simulations of kaolinite platelets in water, toluene, and cyclohexane. Stronger

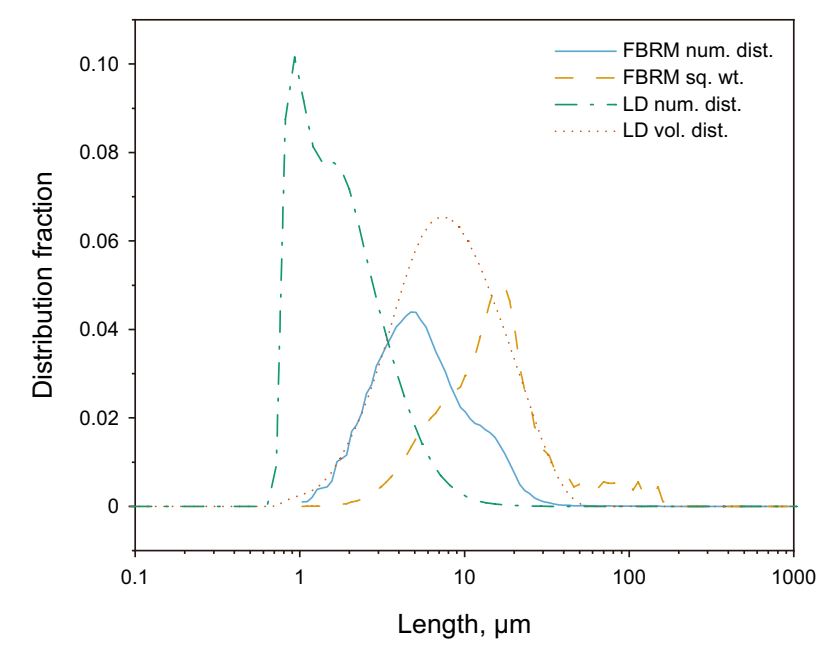

Fig. 4 Chord length distribution of kaolinite particles suspended in a $10 \mathrm{wt} \%$ bitumen solution in toluene: number-average chord length distribution (blue solid line), square weighted average chord length distribution (orange dashed line) measured using FBRM. Particle size distribution of kaolinite in water: number-average distribution (green dotted dashed line) and volume-average distribution (red dotted line), measured using laser diffraction (LD) short-range attractive forces are present in cyclohexane and toluene than in water (Hlushak et al. 2016; Hlushak and Kovalenko 2017). These FBRM results demonstrate that the chord length distribution can be measured under experimental conditions that consist of a dark $10 \mathrm{wt} \%$ bitumen solution. Although chord lengths are not the same measure as particle sizes, as determined by conventional laser diffraction techniques (Heath et al. 2002), the trends in the data are the same and allow to demonstrate whether particle aggregation would occur.

\subsection{Flocculation}

The polymers that were found to be soluble, or sparingly soluble, in toluene were tested for their flocculation performance at increasing dosages from $500 \mathrm{mg}$ of polymer $/ \mathrm{kg}$ of solids in suspension to $50,000 \mathrm{mg} / \mathrm{kg}$. If flocculation was to occur, then a shift in the chord length distribution to higher values would be expected. Figure 5 summarizes a sampling of experiments using kaolinite in a $10 \mathrm{wt} \%$ bitumen solution in toluene.

All tested polymers failed to flocculate kaolinite as measured by the FBRM probe. This suggests that either no flocculation occurred or, if it did occur, it happened at such low rates that it could not be observed by FBRM. Failure to flocculate could be a result of polymers failing to adsorb onto the clay surface or a failure of adsorbed polymers to act as bridges promoting flocculation. Adsorption tests using FTIR to detect polymer adsorbed on the clay surface were performed to determine whether polymer adsorption was the limiting step, as described in Supplementary Information Figs. S1 and S2. Based on the conducted adsorption screening tests, no polymer was detected on the clay samples after mixing and washing. Alternative techniques to monitor flocculation and polymer adsorption should be used to confirm these findings.

Of the polymers tested, PEO and PMA exhibited a slight decrease in the number of particle counts, as can be seen in Fig. 5. No change in aggregate size was detected, and the mean square chord length remained stable throughout the experiment. We speculate that some particles did aggregate and settle out of solution without being detected by the FBRM, but did not occur in large enough quantities to have any measurable effect on the particle sizes. The use of PEO to aid in the sedimentation of kaolinite in cyclohexane was recently demonstrated (Ngnie et al. 2018). Therefore, this hypothesis has some merit but, at this scale and size of particles, no firm conclusions can be drawn.

Finding a polymer that is both soluble in the desired solvent and that will interact with clays is a fine balance. It appears, from the present work, that the polymers used did not interact appreciably with the hydrophilic clays. 

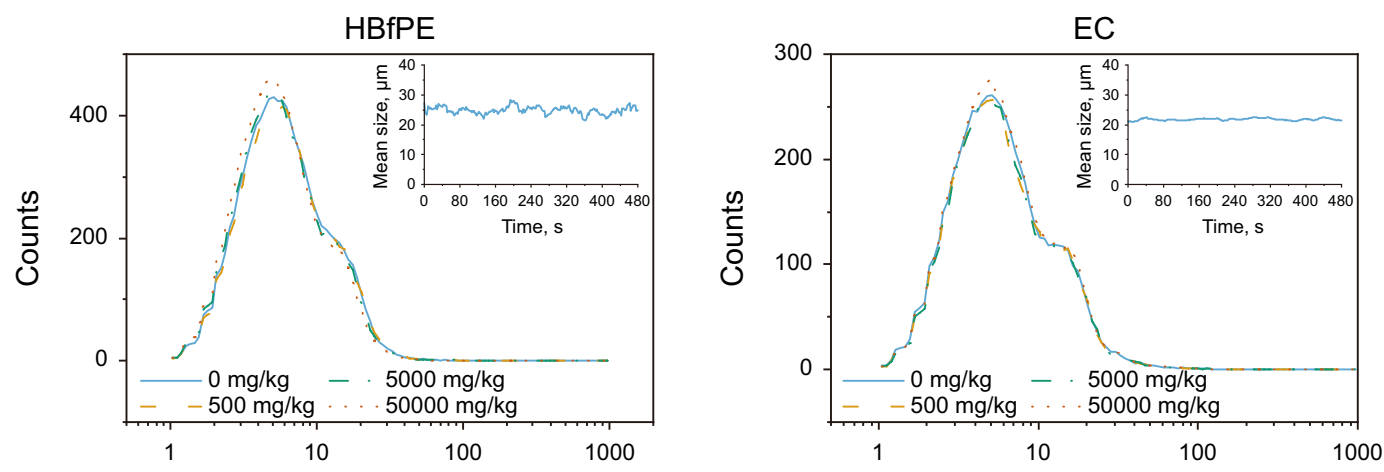

Chord length, $\mu \mathrm{m}$
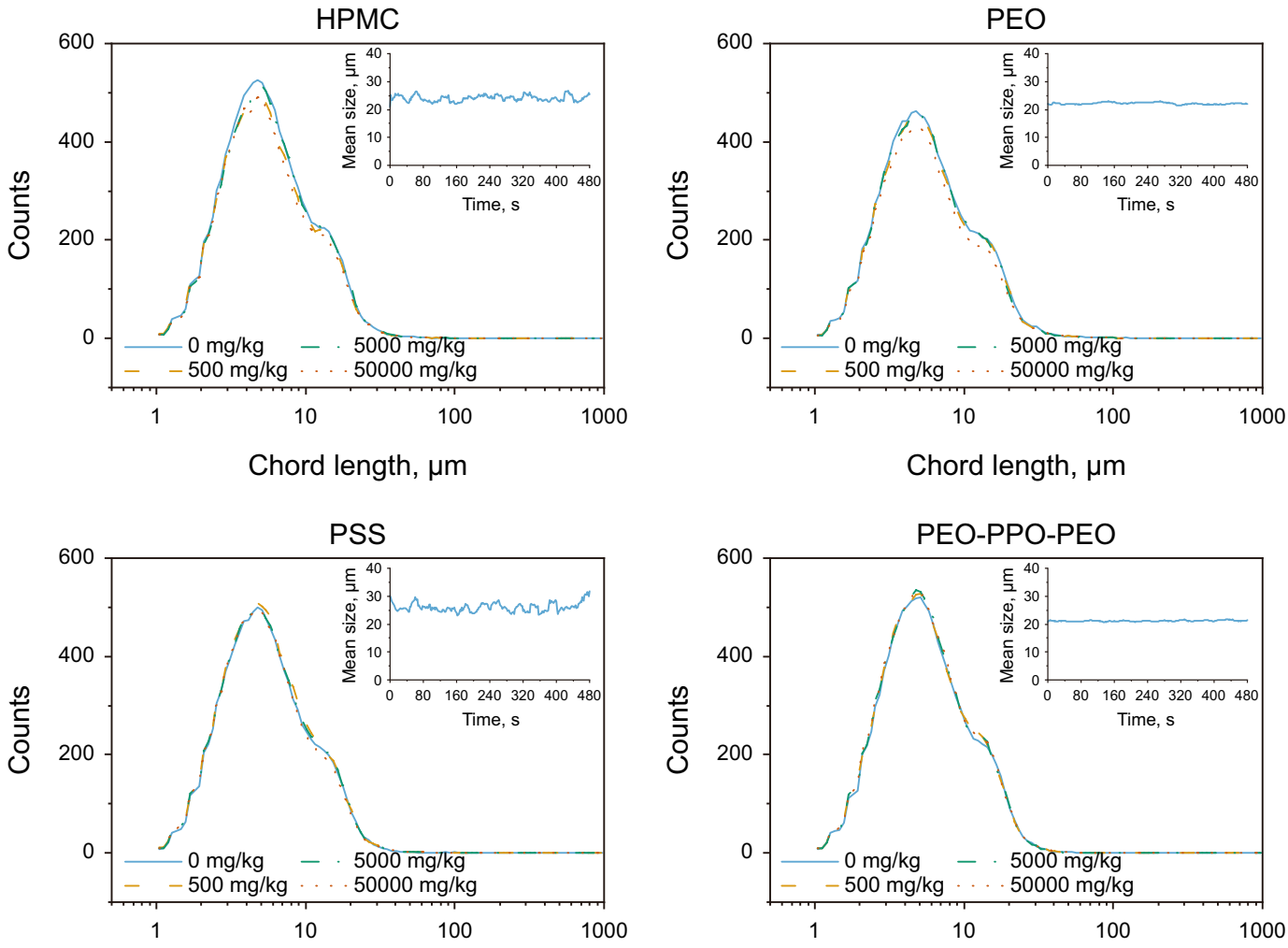

Chord length, $\mu \mathrm{m}$

Chord length, $\mu \mathrm{m}$

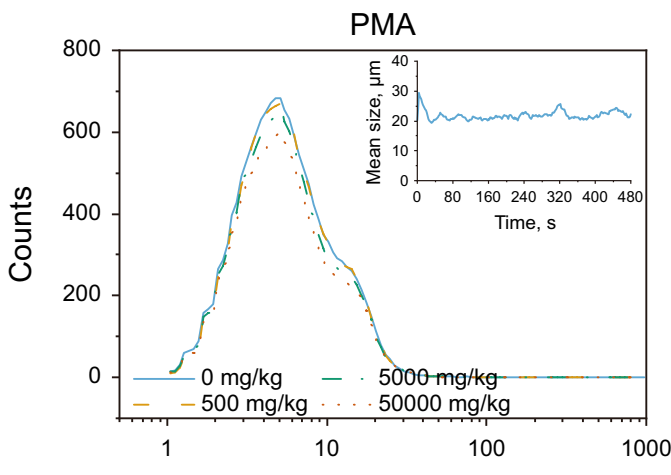

Chord length, $\mu \mathrm{m}$

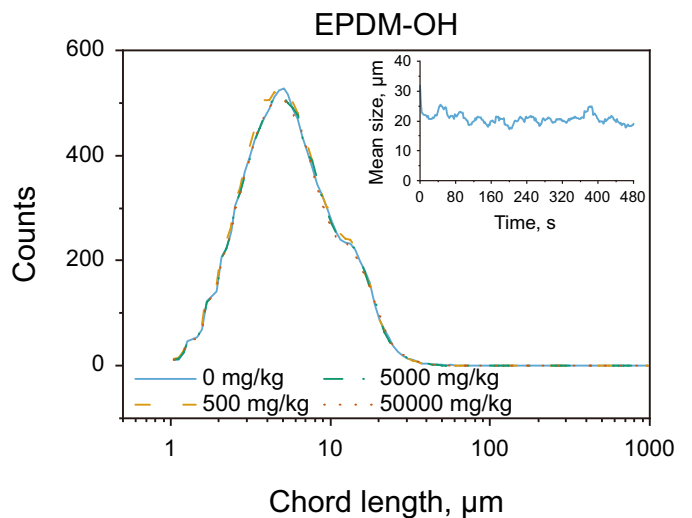

Fig. 5 Chord length distribution (CLD) in bitumen-treated kaolinite suspended in a $10 \mathrm{wt} \%$ bitumen in toluene solution, before (solid line) and after (dashed line) polymer addition monitored using the FBRM technique. Insets: Mean square weighted chord length over the course of the experiment 


\subsection{Sedimentation}

Monitoring the sedimentation of solids using a force tensiometer is an alternative method to measure the rate of solids settling out of suspension. This technique is particularly useful because more common optical techniques, such as changes in turbidity or optical density, are limited to mostly translucent solutions. To verify the findings from the FBRM experiments, several flocculation experiments were monitored using the sedimentation probe.

Figure 6 presents the results from mass accumulation measurements over time on the sedimentation probe, in the presence of PSS or HBfPE in doses of $5000 \mathrm{ppm}$. The slopes showing the initial and final sedimentation rates with and without polymer addition are very similar. The initial settling rates are $0.04 \pm 0.01 \mathrm{mg} / \mathrm{s}$ for HBfPE and $0.06 \pm 0.01 \mathrm{mg} / \mathrm{s}$ for kaolinite and PSS. Steady rates of $0.013 \pm 0.003 \mathrm{mg} / \mathrm{s}$ for HBfPE, $0.014 \pm 0.004 \mathrm{mg} / \mathrm{s}$ for PSS, and $0.016 \pm 0.004 \mathrm{mg} / \mathrm{s}$ for kaolinite are measured after $2 \mathrm{~min}$. The results show that the rate of mass sedimentation is not altered to a statistically significant extent.

None of the polymers screened conclusively indicate the occurrence of any aggregation or flocculation of particles in bitumen-rich organic media. The complexity of the bitumen medium makes it difficult to isolate and identify specific factors that may have affected the flocculation performance. Predicting structures that are soluble in petroleum and act as flocculants is challenging. Additional fundamental understanding of the clay and bitumen, and how these interact with polymers, would be needed. Some recent experiments have been conducted with polymer-modified organo-clays

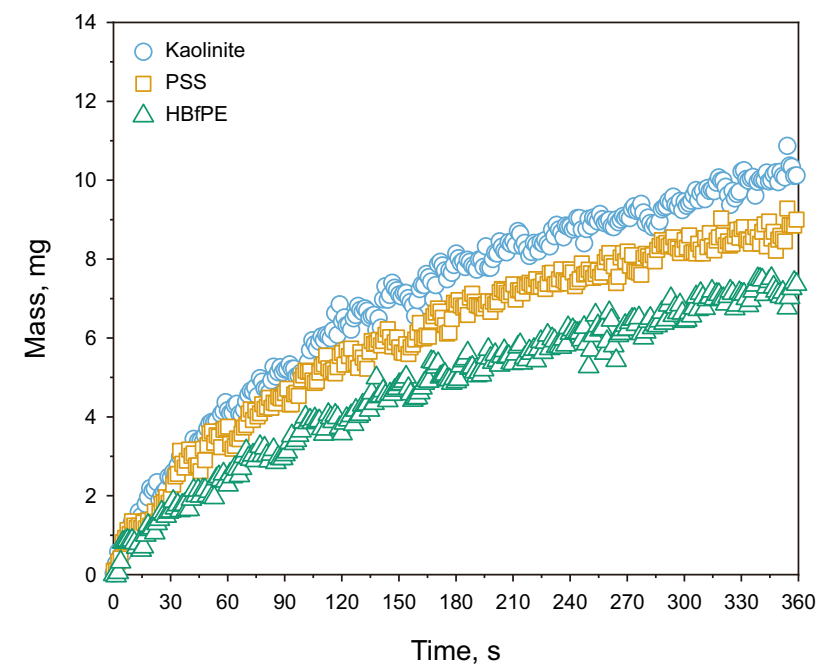

Fig. 6 Sedimentation of kaolinite in a $10 \mathrm{wt} \%$ bitumen solution in toluene. Circles: sedimentation with no polymer added. Squares: Sedimentation with $5000 \mathrm{mg} / \mathrm{kg}$ polystyrene sulfonate (PSS) added. Triangles: Sedimentation with $5000 \mathrm{mg} / \mathrm{kg}$ hyperbranched functionalized polyethylene (HBfPE) added suspended in cyclohexane that indicate flocculation may be possible, but adapting this work to bitumen-rich media would require an extensive effort (Ngnie et al. 2018).

\section{Conclusions}

A way to improve the removal of solids from diluted bitumen produced using naphthenic froth treatment and non-aqueous bitumen extraction processes is still desired. Polymer flocculants could help improve the effectiveness of separation of solids from bitumen, reducing the energy required for mechanical separation. Effective polymer flocculants must be hydrophobic for enhanced solubility (or dispersibility in petroleum) and contain polar or charged groups for bonding to fine solid particles. Candidates with potential include hydrophobic polymers with hydrophilic branches, block copolymers containing a main hydrophobic chain with hydrophilic chain ends, and random copolymers containing hydrophilic and hydrophobic monomers. As part of the evaluation of polymer candidates from these types with respect to solubility in hydrocarbon media and flocculation effectiveness, experimental techniques for determination of flocculation and sedimentation in dark and opaque media are identified. Observations show that the polymers tested do not exhibit notable flocculation effects on kaolinite in toluene, highlighting the challenges arising from the polymer selection requirements and demonstrating that significant rethinking is needed on how to develop polymer flocculants for non-aqueous media.

Developing new polymers to address the removal of fine solids from diluted bitumen is a potentially significant opportunity. A new class of oil-soluble polymer flocculants would facilitate the flocculation and sedimentation of solids out of the bitumen phase. In addition to being bitumen-soluble, the polymer flocculants must be able to extend in the diluted bitumen in order to bind and bring together multiple fine particles to form dense flocs. Polymer compositions and structures containing an oleophilic backbone for enhanced solubility in bitumen and hydrophilic functional groups for binding to solids would be of interest. A fundamental understanding of how polymer flocculants would behave in complex mixtures of bitumen, solvent, and mineral solids is a non-trivial challenge that offers the opportunity to effectively guide the development of the polymer structure and composition. Such understanding could also benefit the optimization of existing bitumen extraction processes.

Open Access This article is licensed under a Creative Commons Attribution 4.0 International License, which permits use, sharing, adaptation, distribution and reproduction in any medium or format, as long as you give appropriate credit to the original author(s) and the source, provide a link to the Creative Commons licence, and indicate if changes were made. The images or other third party material in this article are 
included in the article's Creative Commons licence, unless indicated otherwise in a credit line to the material. If material is not included in the article's Creative Commons licence and your intended use is not permitted by statutory regulation or exceeds the permitted use, you will need to obtain permission directly from the copyright holder. To view a copy of this licence, visit http://creativecommons.org/licenses/by/4.0/.

\section{References}

Berg JC. An introduction to interfaces and colloids: the bridge to nanoscience. Singapore: World Scientific; 2010.

Botha L, Davey S, Nguyen B, Swarnakar AK, Rivard E, Soares JBP. Flocculation of oil sands tailings by hyperbranched functionalized polyethylenes (HBfPE). Miner Eng. 2017;108:71-82. https://doi. org/10.1016/j.mineng.2017.02.004.

Botha L, Soares JBP. The influence of tailings composition on flocculation. Can J Chem Eng. 2015;93(9):1514-23.

Chung TC, Janvikul W, Bernard R, Jiang GJ. Synthesis of ethylene-propylene rubber graft copolymers by borane approach. Macromolecules. 1994;27(1):26-31. https://doi.org/10.1021/ma00079a004.

Clark KA, Pasternack DS. Hot water seperation of bitumen from Alberta bituminous sand. Ind Eng Chem. 1932;24(12):1410-6. https://doi.org/10.1021/ie50276a016.

Dickinson E, Eriksson L. Particle flocculation by adsorbing polymers. Adv Colloid Interface Sci. 1991;34(C):1-29. https://doi. org/10.1016/0001-8686(91)80045-L.

Ese M-H, Sjöblom J, Djuve J, Pugh R. An atomic force microscopy study of asphaltenes on mica surfaces. Influence of added resins and demulsifiers. Colloid Polym Sci. 2000;278(6):532-8. https:// doi.org/10.1007/s003960050551.

Gregory J. Rates of flocculation of latex particles by cationic polymers. J Colloid Interface Sci. 1973;42(2):448-56. https://doi. org/10.1016/0021-9797(73)90311-1.

Gregory J, Barany S. Adsorption and flocculation by polymers and polymer mixtures. Adv Colloid Interface Sci. 2011;169(1):1-12. https://doi.org/10.1016/j.cis.2011.06.004.

Gumfekar SP, Soares JBP. A novel hydrophobically-modified polyelectrolyte for enhanced dewatering of clay suspension. Chemosphere. 2018;194:422-31. https://doi.org/10.1016/j.chemospher e.2017.12.009.

Gupta JK, Basu S. Simultaneous aggregation and sedimentation of silica particles in the presence of surfactants. Colloids Surf Physicochem Eng Asp. 2005;255(1-3):139-43. https://doi.org/10.1016/j. colsurfa.2004.12.010.

Hansen C. Hansen solubility parameters. New York: CRC Press; 2007. https://doi.org/10.1201/9781420006834.

He L, Lin F, Li X, Sui H, Xu Z. Interfacial sciences in unconventional petroleum production: from fundamentals to applications. Chem Soc Rev. 2015;44(15):5446-94. https://doi.org/10.1039/C5CS0 0102A.

Heath AR, Fawell PD, Bahri PA, Swift JD. Estimating average particle size by focused beam reflectance measurement (FBRM). Part Part Syst Character. 2002;19(2):84-95. https://doi.org/10.1002/15214117(200205)19:2\%3c84:AID-PPSC84\%3e3.0.CO;2-1.

Hlushak S, Kovalenko A. Effective interactions and adsorption of heterocyclic aromatic hydrocarbons in kaolinite organic solutions studied by 3D-RISM-KH molecular theory of solvation. J Phys Chem C. 2017;121(40):22092-104. https://doi.org/10.1021/acs. jpcc.7b06414.

Hlushak S, Stoyanov SR, Kovalenko A. A 3D-RISM-KH molecular theory of solvation study of the effective stacking interactions of kaolinite nanoparticles in aqueous electrolyte solution containing additives. J Phys Chem C. 2016;120(38):21344-57. https://doi. org/10.1021/acs.jpcc.6b03786.

Kaminsky HAW, Etsell TH, Ivey DG, Omotoso O. Distribution of clay minerals in the process streams produced by the extraction of bitumen from athabasca oil sands. Can J Chem Eng. 2009;87(1):8593. https://doi.org/10.1002/cjce.20133.

Karkooti A. Aggregation and sedimentation of fine solids in non-aqueous media. Edmonton: University of Alberta; 2014.

Li H, Long J, Xu Z, Masliyah JH. Synergetic role of polymer flocculant in low-temperature bitumen extraction and tailings treatment. Energy Fuels. 2005;19(3):936-43. https://doi.org/10.1021/ef049 $744 \mathrm{e}$.

Li H, Long J, Xu Z, Masliyah JH. Novel polymer aids for low-grade oil sand ore processing. Can J Chem Eng. 2008;86(2):168-76. https ://doi.org/10.1002/cjce.20030.

Li H, Zhou J, Chow R, Adegoroye A, Najafi AS. Enhancing treatment and geotechnical stability of oil sands fine tailings using thermo-sensitive poly(n-isopropyl acrylamide). Can J Chem Eng. 2015;93(10):1780-6. https://doi.org/10.1002/cjce.22276.

Lin F, Stoyanov SR, Xu Y. Recent advances in nonaqueous extraction of bitumen from mineable oil sands: a review. Org Process Res Dev. 2017;21(4):492-510. https://doi.org/10.1021/acs.oprd.6b003 57.

Long J, Li H, Xu Z, Masliyah JH. Role of colloidal interactions in oil sand tailings treatment. AIChE J. 2006;52(1):371-83. https://doi. org/10.1002/aic.10603.

Long J, Li H, Xu Z, Masliyah JH. Improving oil sands processability using a temperature-sensitive polymer. Energy Fuels. 2011;25(2):701-7. https://doi.org/10.1021/ef1012819.

Lower Athabasca Region: tailings management framework for mineable Athabasca oil sands. 2015.

Lu H, Wang Y, Li L, Kotsuchibashi Y, Narain R, Zeng H. Temperatureand $\mathrm{pH}$-responsive benzoboroxole-based polymers for flocculation and enhanced dewatering of fine particle suspensions. ACS Appl Mater Interfaces. 2015;7(49):27176-87. https://doi.org/10.1021/ acsami.5b09874.

Lu H, Xiang L, Cui X, Liu J, Wang Y, Narain R, et al. Molecular weight dependence of synthetic glycopolymers on flocculation and dewatering of fine particles. Langmuir. 2016a;32(44):11615-22. https ://doi.org/10.1021/acs.langmuir.6b03072.

Lu Q, Yan B, Xie L, Huang J, Liu Y, Zeng H. A two-step flocculation process on oil sands tailings treatment using oppositely charged polymer flocculants. Sci Total Environ. 2016b;565:369-75. https ://doi.org/10.1016/j.scitotenv.2016.04.192.

Mark JE, editor. Physical properties of polymers handbook. New York: Springer; 2007. https://doi.org/10.1007/978-0-387-69002-5.

Marlow B, Sresty G, Hughes R, Mahajan O. Colloidal stabilization of clays by asphaltenes in hydrocarbon media. Colloids Surf. 1987;24(4):283-97. https://doi.org/10.1016/0166-6622(87)80235 $-4$.

Mazzeo CPP, Stedille FA, Mansur CRE, Ramos ACS, Lucas EF. Flocculation of asphaltenes by polymers: influence of polymer solubility conditions. Energy Fuels. 2018;32(2):1087-95. https://doi. org/10.1021/acs.energyfuels.7b02577.

Morrison ID. Electrical charges in nonaqueous media. Colloids Surf Physicochem Eng Asp. 1993;71(1):1-37. https://doi. org/10.1016/0927-7757(93)80026-B.

Mowla D, Naderi A. Experimental study of drag reduction by a polymeric additive in slug two-phase flow of crude oil and air in horizontal pipes. Chem Eng Sci. 2006;61(5):1549-54. https://doi. org/10.1016/j.ces.2005.09.006.

Napper DH. Flocculation studies of non-aqueous sterically stabilized dispersions of polymer. Trans Faraday Soc. 1968;64(1):1701. https://doi.org/10.1039/tf9686401701.

Natarajan A, Xie J, Wang S, Masliyah J, Zeng H, Xu Z, et al. Understanding molecular interactions of asphaltenes in organic 
solvents using a surface force apparatus. J Phys Chem C. 2011;115(32):16043-51. https://doi.org/10.1021/jp2039674.

Ngnie G, Baitan D, Dedzo GK, Detellier C. Sedimentation of fine particles of kaolinite and polymer-coated kaolinite in cyclohexane: Implications for fines removal from extracted bitumen in non-aqueous processes. Fuel. 2018;234:218-24. https://doi. org/10.1016/j.fuel.2018.07.032.

Nikakhtari H, Vagi L, Choi P, Liu Q, Gray MR. Solvent screening for non-aqueous extraction of Alberta oil sands. Can J Chem Eng. 2013;91(6):1153-60. https://doi.org/10.1002/cjce.21751.

Pal K, Nogueira Branco LDP, Heintz A, Choi P, Liu Q, Seidl PR, et al. Performance of solvent mixtures for non-aqueous extraction of alberta oil sands. Energy Fuels. 2015;29(4):2261-7. https://doi. org/10.1021/ef502882c.

Pensini E, Harbottle D, Yang F, Tchoukov P, Li Z, Kailey I, et al. Demulsification mechanism of asphaltene-stabilized water-inoil emulsions by a polymeric ethylene oxide-propylene oxide demulsifier. Energy Fuels. 2014;28(11):6760-71. https://doi. org/10.1021/ef501387k.

Rao F, Liu Q. Froth treatment in athabasca oil sands bitumen recovery process: a review. Energy Fuels. 2013;27(12):7199-207. https:// doi.org/10.1021/ef4016697.

Reis LG, Oliveira RS, Palhares TN, Spinelli LS, Lucas EF, Vedoy DRL, et al. Using acrylamide/propylene oxide copolymers to dewater and densify mature fine tailings. Miner Eng. 2016;95:2939. https://doi.org/10.1016/j.mineng.2016.06.005.

Szilagyi I, Trefalt G, Tiraferri A, Maroni P, Borkovec M. Polyelectrolyte adsorption, interparticle forces, and colloidal aggregation. Soft Matter. 2014;10(15):2479. https://doi.org/10.1039/c3sm5 $2132 \mathrm{j}$.
Tchoukov P, Yang F, Xu Z, Dabros T, Czarnecki J, Sjöblom J. Role of asphaltenes in stabilizing thin liquid emulsion films. Langmuir. 2014;30(11):3024-33. https://doi.org/10.1021/la404825g.

Vajihinejad V, Gumfekar SP, Bazoubandi B, Rostami Najafabadi Z, Soares JBP. Water soluble polymer flocculants: synthesis, characterization, and performance assessment. Macromol Mater Eng. 2019;304(2):1800526. https://doi.org/10.1002/mame.201800526.

Vajihinejad V, Soares JBP. Monitoring polymer flocculation in oil sands tailings: a population balance model approach. Chem Eng J. 2018;346(1):447-57. https://doi.org/10.1016/j.cej.2018.04.039.

Vedoy DRL, Soares JBP. Water-soluble polymers for oil sands tailing treatment: a review. Can J Chem Eng. 2015;93(5):888-904. https ://doi.org/10.1002/cjce.22129.

Wang S, Liu J, Zhang L, Xu Z, Masliyah J. Colloidal interactions between asphaltene surfaces in toluene. Energy Fuels. 2009;23(2):862-9. https://doi.org/10.1021/ef800812k.

Wang S, Zhang L, Yan B, Xu H, Liu Q, Zeng H. Molecular and surface interactions between polymer flocculant chitosan $\mathrm{g}$ polyacrylamide and kaolinite particles: impact of salinity. J Phys Chem C. 2015;119(13):7327-39. https://doi.org/10.1021/acs.jpcc.5b00739.

Wu J, Xu Y, Dabros T, Hamza H. Effect of EO and PO positions in nonionic surfactants on surfactant properties and demulsification performance. Colloids Surf Physicochem Eng Asp. 2005;252(1):79_ 85. https://doi.org/10.1016/j.colsurfa.2004.09.034.

Zhu Y, Tan X, Liu Q. Dual polymer flocculants for mature fine tailings dewatering. Can J Chem Eng. 2017;95(1):3-10. https://doi. org/10.1002/cjce.22628. 